\title{
Análisis de los derechos reconocidos a los pueblos originarios en el Derecho Comparado (el caso de las comunidades autóctonas en México y las tribus de los Estados Unidos de Norteamérica)
}

\author{
Roxana Paola Miranda Torres* \\ Recibido: 3 de Agosto \\ Dictaminado: 22 de Septiembre
}

\section{Resumen}

En el presente trabajo de investigación se realiza un análisis de la problemática social y jurídica de los pueblos originarios de México y de manera específica en relación a su personalidad jurídica, su tratamiento en la historia en el constitucionalismo mexicano y las últimas reformas en la materia. Además, desde la perspectiva del Derecho comparado consideramos la situación de los pueblos amerindios o tribus de los Estados Unidos de Norteamérica, su tratamiento en la legislación y la comparación en este tema de los sistemas jurídicos mexicano y norteamericano.

Palabras clave: Pueblo Originario, Personalidad Jurídica, Constitución, Tribus, Sistemas Jurídicos.

\section{Analysis of the rights recognized to the original peoples in}

\section{Comparative Law (the case of indigenous communities in Mexico and the tribes of the United States of North America)}

\begin{abstract}
In the present work of investigation an analysis of the social and juridical problematic of the native towns of Mexico and of specific way in relation to its legal personality, its treatment in the history in the Mexican constitutionalism and the last reforms in the matter are realized. In addition, from the comparative law perspective, we consider the situation of Amerindian peoples or tribes of the United States of North America, their treatment in legislation and comparison in this subject of Mexican and American legal systems.
\end{abstract}

*Universidad Panamericana.rmiranda@up.edu.mx 
Key words: Originating People, Legal Personality, Constitution, Tribes, Legal System.

\section{Sumario}

I. Introducción; 1.1 México y sus pueblos originarios; 1.2. Los pueblos originarios en el constitucionalismo mexicano; II. Los Estados Unidos de Norteamérica y sus tribus; III. El tratamiento de los pueblos originarios en la Constitución Norteamericana; IV. Los pueblos amerindios en la legislación norteamericana; V. Análisis comparativo de los distintos sistemas jurídicos en relación a las comunidades autóctonas, tribus o pueblos amerindios (México y Estados Unidos de Norteamérica); VI. Conclusiones; Bibliografía

\section{Introducción}

\subsection{México y sus pueblos originarios}

En la actualidad, la mayoría de los países cuentan con un pluralismo cultural y jurídico, aquellos donde todos los ciudadanos hablan el mismo idioma y pertenecen al mismo grupo étnico son una excepción. Tal pluriculturalidad genera una influencia sobre la vida política, social y económica de muchos países y todo ello impacta en el ámbito normativo, dada la diversidad de agrupaciones humanas que se interrelacionan, ya sean las mayorías y las minorías culturales, mismas que enfrentan una realidad compleja y difícil en el tema de los derechos lingüísticos, la autonomía, la personalidad jurídica, la educación, la lengua, las políticas de inmigración y de naturalización, su reconocimiento jurídico y demás aspectos culturales cada vez más sincréticos y que nos llevan a transformaciones difíciles de predecir (Bonilla Maldonado, 2006).

En este orden de ideas, nuestro país está constituido como una federación, 32 estados y más de 120 millones de habitantes, de los cuales el 7\% pertenece a un pueblo originario, aunque esta cifra podría duplicarse ya que no se cuentan los menores de cinco años ni los indígenas que niegan su origen para no ser discriminados (Estadísticas históricas del INEGI, 2010). Se trata de 63 grupos aproximadamente que tienen presencia en todo el país, pero principalmente en los estados de Oaxaca, Campeche, Chiapas, Chihuahua, Guerrero, Hidalgo, 
Estado de México, Michoacán, Puebla, Quintana Roo, San Luis Potosí, Veracruz y Yucatán de manera principal (www.inegi.com.mx consultada el 14 de agosto de 2017, s.f.).

Dichos entes federados, con excepción del Estado de México son los de mayor marginación o pobreza, su analfabetismo es elevado y muchos de ellos ni siquiera hablan castellano o lengua española, que es el idioma oficial del país (Centro de estudios municipales, 2016).

El artículo siete de la Ley sobre derechos y el desarrollo de los pueblos y las comunidades indígenas del Estado de Jalisco define a la comunidad indígena como la entidad de interés público constituida por un conjunto de personas que pertenecen a un determinado grupo indígena, que forman una unidad social, económica y cultural, asentada en un territorio y que reconocen autoridades propias de acuerdo a sus usos y costumbres. Al considerarse indígenas como pueblos descendientes de los habitantes originarios de muchas zonas del planeta, no significa que el resto de la población proceda de otro mundo, pero en específico los indígenas, autóctonos u originarios mantienen numerosos rasgos culturales que representan una comunidad más directa de culturas diferenciadoras atestiguadas desde hace milenios.

Sin embargo y a reserva de seguir perfeccionando la denominación, consideramos que el término más adecuado para nombrar a las comunidades indígenas es el de comunidades autóctonas, precuauhtemicas o pueblos originarios, en el entendido que comunidad significa unión, comunión e integración de valores, principios e intereses, lo cual es una realidad tangible en dichos grupos; en otro sentido son aborígenes, autóctonos u originarios cuyas referencias raciales, religiosas y culturales datan desde la época de Cuauhtémoc o de la llegada de los ibéricos, época de conquista o colonización de México, por ello, estas comunidades no son "indias" son autóctonas, aborígenes de estas tierras mestizas en forma ancestral, sus elementos raciales, de poligamia, de politeísmo, constituyen cada grupo en particular o en conjunto diversidades específicas (Miranda Torres, 2008). 


\subsection{Los pueblos originarios en el constitucionalismo mexicano}

En la actualidad, la realidad de los pueblos originarios ha llamado la atención de nacionales como extranjeros, sin embargo, no tenemos una visión muy clara de lo que estos representan para México, América y el Mundo, su estado de conservación, sus conocimientos, sus expectativas del futuro y sobre todo su régimen jurídico actual (Florescano, 1998).

La problemática de dichos pueblos ha pasado por varias etapas en la historia de nuestro país, desde la conquista, la Revolución Mexicana, así, se ve claramente reflejada su situación en el constitucionalismo mexicano hasta arribar a la Constitución de 1917 (Covarrubias Dueñas, 2014), etapa donde se intentó integrar a dichas comunidades, y finalmente una etapa de reconocimiento con las reformas constitucionales de 1992, 2001 y 2015.

A pesar de los derechos reconocidos en las ya citadas reformas constitucionales, la situación de las comunidades autóctonas es incierta y confusa, sus problemas tienen que ver con su derecho a la justicia, a la cultura, a la identidad y a la negación de su propia identidad. No tienen un marco jurídico que garantice, de manera efectiva su núcleo básico autonómico, de acuerdo a los siguientes supuestos:

a) El proceso de colonización hacia estas comunidades está siempre presente, la autonomía indígena deber ser comprendida desde su contexto histórico ya que se enfrentan al sistema capitalista.

b) Las comunidades autóctonas en México son víctimas de inequidad y discriminación (González Galván, 2010).

c) Una de las asignaturas pendientes en el proceso de democratización de México sigue siendo la relacionada con la extensa y profunda pobreza, marginación, invisibilidad y discriminación que sufren los indígenas del país. El diseño e instrumentación de políticas públicas que han demostrado una y otra vez ser incapaces de generar niveles de justicia, igualdad de oportunidades y equidad entre los pueblos indígenas (Instituto de Estudios del Federalismo, 2003).

d) Falta de reconocimiento de las comunidades autóctonas por las 
legislaciones locales, lo que les impide entre otras cosas acceder a programas sociales del gobierno federal ${ }^{1}$.

e) No cuentan con representación política en los poderes formales que atienda a sus intereses, son raros los miembros indígenas que se han integrado en alguno de los poderes, este es un vacío que se debe cuestionar. De igual forma el 22 de mayo de 2015, se publicó una reforma donde se estableció la igualdad política entre las mujeres y los hombres, en el sentido de que deben de ser votadas las mujeres en las mismas condiciones que los hombres, en armonía a los demás preceptos de nuestra Constitución.

f) No conocemos su cultura, tradiciones, religión, costumbres, formas de ser y de pensar, los sentimos ajenos y a la inversa, no constituimos una unidad o identidad, existen muchas idiosincrasias en México sin un proyecto común, dificultades para lograr una Constitución democrática.

En conclusión, el Gobierno mexicano no ha sentado las bases adecuadas para que las comunidades autóctonas se hagan cargo de sus asuntos por la vía del derecho a la autonomía y a la libre determinación porque aunque se les otorgan estos derechos sustantivos en el artículo segundo constitucional, no se les otorga personalidad jurídica, no se les reconoce como sujetos de derecho; así, el núcleo constitucional de prerrogativas de que gozan dichas comunidades autóctonas, queda vacío en la realidad efectiva y por tanto, dichos avances, han quedado en declaraciones utópicas ${ }^{2}$.

En este orden de ideas, ¿cómo se podría proteger una comunidad autóctona ante el posible abuso de un particular, del sector social o del sector público (federación, estados o municipios)?; en el mismo sentido ¿sobre quién recaerá la representación dentro de dichos grupos en la defensa de sus intereses?, ¿se toman en cuenta sus tradiciones, usos y costumbres en los juicios donde forman parte?,

\footnotetext{
1 Es muy lamentable el hecho de que la reforma del DOF a los artículos 1, 2, 4, 18 y 115; señala en el precepto del 115, que en el mejor de los casos, cuando la población autóctona sea numerosa, entonces, dichos grupos, podrán tener algún representante en al ayuntamiento, lo cual es contrario a la naturaleza de la autonomía política y la libre autodeterminación.

2 Se evidencia que el legislador no ha tratado de cumplir los alcances de las propuestas planteadas, ni las demandas de los grupos autóctonos del país; pero lo más lamentable es el hecho de que las aspiraciones de dichas comunidades, ya establecidas en el marco constitucional no se pueden tutelar de manera efectiva, conforma a lo establecido en el artículo 17 CPEUM.
} 
¿tienen las comunidades autóctonas una legislación adecuada para proteger sus intereses?, ¿realmente están resguardados sus derechos?, ¿se respetan las formas tradicionales de matrimonio, filiación, nombres y demás cuestiones jurídicas?

Aunque la situación de las comunidades autóctonas es muy compleja, el asunto de la personalidad jurídica es una cuestión importante de resolver, condictio sine qua non, para que cumplan, de manera eficaz, sus derechos reconocidos formalmente en la legislación mexicana que representan un notable avance, sin embargo, la reforma no satisfizo las sus expectativas respecto del alcance de estos derechos.

Existe la obligación de las legislaturas de las entidades federativas para reglamentar la libre determinación de los pueblos indígenas existentes en su territorio y sólo algunos han cumplido con tal disposición. En este orden de ideas, si hablamos de acceso a la jurisdicción del Estado, vemos las terribles injusticias y vejaciones en que se encuentran los pueblos originarios, desconociendo en todo momento sus garantías. Además un gran desacierto de la reforma de 2001 fue considerar a las comunidades como sujetos de interés público, esto conlleva a negarles su condición como sujetos de derecho, condición indispensable para que lleven a cabo su autonomía y libre determinación, entre otras cuestiones.

Los temas pendientes por abordar para el ejercicio colectivo de los derechos de las comunidades requieren cambios estructurales que permitan la construcción de un estado pluricultural y para que puedan ejercer sus prerrogativas es necesario su reconocimiento como sujetos de derecho, con personalidad jurídica ${ }^{3}$.

Dentro del ámbito jurídico, según el Código Civil de Jalisco, la existencia legal de una persona física, de un individuo, está determinada por alcanzar la mayoría de edad; en el caso de una persona moral de derecho privado se requiere la formalización de un estatuto constitutivo; y cuando se trata de personas morales de derecho público, la emisión de una ley o acto administrativo para integrar su personalidad jurídica como entidad de derecho público.

Las comunidades autóctonas son personas colectivas, su mención y definición en la Constitución Federal no basta para probar su existencia legal,

3 Lo más lamentable del caso es que en materia agraria, sí se les reconoce su personalidad jurídica en lo individual y en lo colectivo; lo cual es una contradicción constitucional y también legal, porque se supone que si se cuentan con dicha facultad para algunas cuestiones no lo es para el todo. 
se requiere de la manifestación expresa del legislador para conformar entidades de derecho público que gocen de personalidad y capacidad jurídica plenas, con todas las consecuencias legales inherentes. Mientras esto no suceda, su existencia no puede ser probada legalmente y por lo tanto, no pueden contraer obligaciones ni ejercer derechos como entidad colectiva (Comisión Nacional para el desarrollo de los pueblos indígenas, 2007).

\section{Los Estados Unidos de Norteamérica y sus tribus}

Los Estados Unidos de Norteamérica son un país constituido en una República Federal, tiene un territorio de 9'629,091 kilómetros cuadrados y está conformado por 50 estados, el Distrito de Columbia, territorios y algunos estados libres y asociados; cuenta con una población de 308'745,538 habitantes de los cuales 72.4\% son blancos, $12.6 \%$ pertenecen a la raza afroamericana, el $16.3 \%$ son hispanos o latinos y el $0.9 \%$ pertenece a una tribu, esto en relación al census 2010 (Census, 2010); tiene una problemática específica en relación a pueblos amerindios, que se ha manifestado a través del tiempo en procesos de reconocimiento, tratados, aniquilación, asimilación, etc.

La denominación tribu tal y como se encuentra en la legislación, contempla a un grupo de indios o native american (nativos americanos) de la misma raza o raza similar, unidos en una comunidad bajo un mismo liderazgo o gobierno, y que habitan un territorio en particular aunque éste no esté precisamente definido (Zamudio, 2011). Los criterios para la conformación de una tribu son los siguientes (Zamudio, 2011):

a) En qué medida los miembros del grupo son personas de ascendencia nativa que viven y fueron criados en una sociedad y comunidad amerindia.

b) En qué medida su vida y sus actividades se hallan bajo el control de un gobierno indio.

c) La participación de sus miembros en los asuntos de la tribu.

d) En qué medida el grupo ejerce control sobre un territorio específico.

f) En qué medida el status político del grupo es reconocido por las 
autoridades federales que tienen el poder y el deber de administrar las relaciones entre los Estados Unidos y los indios.

g) La continuidad histórica de estos factores.

Sin embargo, cada tribu en el ejercicio de su soberanía, determina cuáles son las condiciones para ser considerado miembro de la tribu. En general, el requisito es tener antepasados indígenas. Pero no basta con esto, es necesario establecer una relación con la tribu para ser considerado miembro y se debe estar registrado como miembro. En algunos casos el Secretario del Interior ${ }^{4}$ tiene la obligación de compilar un registro completo de los miembros de la tribu (Departamento del Interior de los Estados Unidos de Norteamerica, 2017). En otros la propia tribu debe de llevar el registro. Además de la pertenencia por lazos de sangre, una persona puede convertirse en miembro de la tribu por matrimonio o adopción.

La Oficina de Asuntos Indígenas reconoce 565 tribus, una tribu no reconocida puede solicitar ese reconocimiento en dicha oficina. En realidad existe un directorio actualizado por Estado de cada una de las tribus que comprende su ubicación (domicilio), datos de su líder o representante, teléfono, fax, sitio web y correo electrónico (Affairs, 2011).

De los estados que integran el territorio norteamericano, todos sin excepción, tienen entre su población a miembros de las tribus o pueblos amerindios y podemos presentar los siguientes datos según el census 2010:

Se presenta un índice más elevado de tribus o pueblos amerindios alcanzando en algunos estados el 5\% hasta casi el 15\% del total de la población como en Alaska, Arizona, Montana, North Dakota, Oklahoma, South Dakota, Nuevo México.

Existen otros estados donde la población de los pueblos amerindios alcanza hasta un 2\% aproximadamente como en los estados de Idaho, Oregon, Washington, Wyoming. Las lenguas nativas de los estados de Oregon, Idahoo, Wynoming, Nevada, Utah, Colorado, California, Arizona y Texas pertenecen al tronco lingüístico yutonahua o yutoazteca; dicho tronco es el mismo del que

\footnotetext{
4 United States Departament of the Interior (DOI), es un departamento del gabinete de los Estados Unidos que gestiona y conserva las tierras de propiedad federal y administra los programas relacionados con los pueblos indígenas de los Estados Unidos y sus territorios inusuales, tiene un presupuesto aproximado de 16.8 billones de dólares.
} 
derivan distintas lenguas de las comunidades autóctonas mexicanas como el pima alto, el tepehuáno tepecano, el tarahumara-varohío, el yaqui y el mayo, el cora, el huichol, el náhuatl y el mexicano o azteca ${ }^{5}$, por lo que se piensa que los primeros pobladores llegaron al norte de América y de ahí se extendieron hacia centro y sur América (Hernández de León Portilla, 2011).

Uno de cada cuatro estadounidenses pertenece a las minorías raciales étnicas más grandes. Para el año 2050, los grupos blancos habrán descendido a $52.7 \%$ de la población, los hispanos serán la minoría más numerosa con $21.1 \%$; los negros representarán $16.2 \%$, los asiáticos, $10.7 \%$ y los indios americanos, $1.2 \%$, se considera que existen alrededor de dos millones de individuos pertenecientes a una tribu (González Gutiérrez, 1996).

\section{EI tratamiento de los pueblos originarios en la Constitución Norteamericana}

"La Constitución de los Estados Unidos fue concebida y escrita hace más de dos siglos, y aún señorea en el centro del sistema político de aquel país" (Toinet, 1994). Cualquier proceso político gira alrededor de esta ley fundamental, concisa (siete artículos, 27 enmiendas), la más antigua entre las que se encuentran vigentes, menciona brevemente a los pueblos amerindios en tres ocasiones.

En el Artículo I, Segunda Sección, modificado posteriormente por la decimocuarta enmienda (adoptada en 1868), que hace referencia a las tribus como sujetos de tributación como excluidas del cálculo de población en base al que los estados deben elegir a sus representantes.

Artículo I. Sección 2. La Cámara de representantes, cómo se establece,

\footnotetext{
5 Hoy sabemos que los hablantes de yutonahua avanzaron del norte al sur del continente hace miles de años, quizá desde lo que hoy es Oregon; llegaron a la actual Sonora hacia 2,500 a.C. y de ahí continuaron su marcha hacia el sur: hacia 400 d.C, los hablantes del protonáhuatl entraron en contacto con el imperio Teotihuacano y poco a poco, se extendieron por lo que llamamos Mesoamérica, habitada desde antes por otros pueblos, dueños de un alto nivel cultural y de grandes civilizaciones. En su largo caminar hacia el sur fueron dejando un rosario de lenguas en zonas montañosas de América del Norte, las tierras altas de la gran cuenca y la Sierra Madre Occidental.
} 
poder para residenciar.

La Cámara de Representantes, se compondrá de miembros elegidos cada dos años por el pueblo de los distintos estados, y los electores en cada Estado cumplirán con los requisitos exigidos a los electores de la rama más numerosa de la asamblea legislativa de dicho Estado.

No podrá ser representante ninguna persona que no haya cumplido los veinticinco años de edad, que no haya sido durante siete años ciudadano de los Estados Unidos y que, al tiempo de su elección, no resida en el Estado que ha de elegirlo.

Tanto los representantes como las contribuciones directas (modificada por la decimosexta Enmienda) se prorratearán entre los diversos Estados que integren la Unión, de acuerdo al número respectivo de sus habitantes, el cual se determinará añadiendo al número total de personas libres, incluyendo a las que estén obligadas al servicio por determinado número de años y excluyendo a los indios que no paguen contribuciones de las tres quintas partes de todas las demás (denegada por la Décimo Cuarta Enmienda)...

En la Octava Sección del Artículo I, conocida como "Cláusula de Comercio" que otorga poder al congreso para regular el comercio, entre otros con las tribus indias.

Sección 8. Poderes del Congreso.

El Congreso tendrá la facultad: ... Para reglamentar el comercio con naciones extranjeras, así como entre los diferentes Estados y con las tribus indias.

De esta mención se deprende que las tribus eran consideradas entidades políticas separadas, externas a los Estados Unidos de Norteamérica, de igual forma concentra en el Congreso todas las facultades para conducir las relaciones del gobierno con las tribus indias.

Por otra parte aunque sin mencionarlas explícitamente en el artículo VI, la Constitución reconoce el status legal de los tratados con las tribus, al afirmar que junto con la Constitución y las leyes, los tratados constituyen la suprema ley del país. 
Artículo VI... La presente Constitución, las leyes de los Estados Unidos que en seguimiento de ella se aprueben y todos los tratados celebrados y que se celebren bajo la autoridad de los Estados Unidos, serán suprema ley del país; los jueces de cada Estado estarán obligados a observarla aun cuando hubiese alguna disposición en contrario en la Constitución o en las leyes de cualquier Estado...

La firma de los tratados con los indios Delaware en 1787 marca el inicio de casi un siglo en que el gobierno federal firmó más de 650 tratados con las naciones indígenas. Los tratados en general tenían cláusulas para el mantenimiento de la paz, los derechos de caza y pesca de los indios, el reconocimiento de parte de las tribus de la autoridad del gobierno federal o su protección. A partir de 1820 los tratados comenzaron a centrarse en la cesión de tierras por parte de las tribus y la creación de reservaciones bajo la protección del gobierno federal, como reflejo de la política del gobierno federal de remoción de los indios de sus territorios originales hacia el oeste, a fin de facilitar la expansión de los Estados Unidos. Estos tratados dieron origen a un vasto sistema de reservaciones, en las cuales los indios podían ejercer sus derechos (Zamudio, 2011).

Esta etapa se caracteriza por la "política de civilización" que siguió el gobierno norteamericano ya que las tribus fueron sometidas a cambios estructurales e ideológicos debido a la reducción de su territorio mediante tratados; la idea era que cedieran tierra de cacería y se dedicasen a la agricultura, para lo cual deberían ser instruidos y este objetivo sólo se podría logar mediante el confinamiento de las tribus en reservaciones (Los casinos de las tribus estadounidenses: ¿un punto para la autodeterminación?).

Por lo tanto, el término de native american reservations proviene de los acuerdos del siglo XIX, en que las tribus cedieron sus tierras al gobierno de los Estados Unidos, excepto las partes "reservadas" para su propio uso, sin embargo, estas tierras eran cada vez más atractivas para los colonos blancos, considerando a los nativos como obstáculo para el progreso. 


\section{Los pueblos amerindios en la legislación norteamericana}

En 1887 se sancionó la Ley General de Loteo, Ley Dawes o General Allotment Act que autorizaba a la oficina de asuntos indígenas a dividir las tierras comunales de las reservaciones en lotes o parcelas para ser entregadas a los miembros de las tribus como propiedad individual, además a quienes recibían tierras se les otorgaba la ciudadanía como forma de acelerar su asimilación. Esta ley fue desastrosa para los indios, la mayoría de las tierras asignadas no eran aptas para la agricultura y terminaban alquilando sus tierras a los blancos. Además el gobierno federal se apropió de la tierra que restaba para destinarla a colonos que llegaban de Europa. El principal efecto fue una severa reducción de la cantidad de las tierras de las tribus de 138 millones de acres en 1887 hasta 48 millones de acres en 1934 (Pevar, 2002), se borraron las fronteras de las reservaciones y los indígenas se asimilaron a la sociedad.

En la década de 1930 surge un replanteamiento de la política indigenista de los Estados Unidos de Norteamérica, el gobierno trató de reforzar la soberanía tribal a través de la Ley de la Reorganización Indígena de 1934.

Esta ley firmada por el presidente Franklin D. Roosevelt, también conocida como la Ley de Wheeler-Howard, fue en los Estados Unidos la legislación federal que aseguró ciertos derechos a los nativos americanos, incluyendo Alaska nativos. Se incluyen acciones que contribuyeron a la reversión de la privatización de la Ley de Dawes de propiedades comunales de las tribus indígenas americanas y el regreso a la autonomía local sobre una base tribal. La Ley también restauró a los nativos americanos de la gestión de sus activos e incluye disposiciones encaminadas a crear una sólida base económica para los habitantes de las reservas indígenas (http://es.zettapedia.com/acta-de-reorganizacion-indigena. htm consultada el 15 de septiembre de 2011).

De esta forma, terminó con el proceso de loteo, autorizó la devolución de tierras remanente de los loteos que aún no hubieran sido vendidas, y promovió el autogobierno en las tribus. Aunque favorecido el gobierno tribal, el gobierno federal no abandonó su obligación de tutela. Esta ley también autorizaba al 
Secretario del Interior a adquirir tierras en nombre de las tribus o miembros individuales, las cuales serían mantenidas en fideicomiso por el gobierno y se autorizaba la creación de nuevas reservaciones. Esta política además de mantener y desarrollar las tierras de las tribus y sus recursos, garantizaba el derecho de los indígenas a tener negocios, establecer un sistema de crédito y de vivienda, así como el diseño de educación especial para ellos.

La siguiente etapa en el desarrollo de la política indígena representó una vuelta al concepto de asimilación. En 1953, el Congreso aprobó la resolución 108, el gobierno instauró la política de finalización de reservaciones y de tribus reconocidas financiadas por el gobierno federal, además de la pérdida de servicios federales, esto implicó la terminación de la relación de tutelaje del gobierno, la reubicación de las tribus en ciudades y la venta de sus tierras.

Posteriormente, el gobierno de los Estados Unidos de Norteamérica decidió romper con el pasado y crear las condiciones para una nueva época en la que las tribus determinaran su propio futuro mediante decisiones y hechos.

A mediados de la década de 1960, como producto del movimiento de los derechos civiles que promovieron las organizaciones afroamericanas, el gobierno estadounidense emprendió una serie de reformas tendientes a promover la igualdad económica, política y social entre los grupos étnicos, con el ánimo de cerrar la brecha que separaba a las personas de color, víctimas tradicionales de discriminación, del sector blanco de la sociedad, en este contexto de da el asesinato de Martin Luther King en 1968. (González Gutiérrez, 1996).

Estas reformas transformaron de manera radical el rol del gobierno en la promoción de los derechos humanos y civiles en los Estados Unidos. El movimiento negro sirvió de modelo (en términos ideológicos como de organización), para esfuerzos de reivindicación de los derechos civiles de otros grupos víctimas de discriminación como las mujeres, los hispanos, los homosexuales, las personas inhabilitadas físicamente, los miembros de agrupaciones religiosas y los demás grupos étnicos.

Fue el momento en que la Indian Civil Rights Act, entró en vigor en 1968, era un paso hacia el autogobierno indio, el cual reduciría la dependencia de los fondos del gobierno federal. En la indian Self-Determination and Education Assistance Act de 1975 se propuso una máxima participación de los indígenas en 
los programas y servicios del gobierno federal destinados a ellos y se estableció un programa de educación indígena. Sin embargo, las tribus no trabajan de forma independiente sino que el Secretario del Interior entra en contacto con ellas para planear, dirigir y administrar programas (Prucha, 1997).

Los casinos empezaron en territorios tribales en la década de los setenta y cómo respuesta a los problemas que se presentaban en su regulación, en 1988 el Congreso promovió la Indian Gaming Regulatory Act, con los objetivos de mantener la soberanía tribal y lograr una mayor autonomía política y económica, además fue atractivo para el gobierno norteamericano porque reducen el presupuesto federal destinado a las tribus. En la administración del presidente Clinton hubo un trato amistoso con las tribus, pero surgieron conflictos entre los Estados y las tribus debido al manejo de los casinos.

Esta ley dice que el Congreso considera que las tierras indias tienen el derecho exclusivo de emprender la actividad del juego, si la ley federal no prohíbe específicamente esta actividad y se efectúa dentro de un Estado donde las leyes penales y la política pública lo permitan. Es decir, de alguna manera otorga y a la vez limita el derecho para juegos de azar, el gobierno federal exige tres requisitos fundamentales: indian land, tribal law y gaming law. Entonces aunque el gobierno federal apruebe el juego, el Estado tiene derecho de prohibirlo de acuerdo con sus leyes.

Las tribus no disponen de una soberanía verdadera; dependen del gobierno federal pero también de los Estados, porque el gobierno federal define las diferentes clases de juego, y el Estado concede los permisos para los mismos.

Además, a través de los casinos, la integración de las tribus al sistema capitalista es inevitable, la juventud está sometida a la educación estadounidense y muy influida por los medios de comunicación que moldean su ideología al estilo del país; los jóvenes indígenas se sienten muy atraídos por el alcohol y las drogas, adicciones que perjudican su personalidad y sus relaciones sociales. Esta manipulación ideológica pone en peligro su permanencia cultural. El éxito económico de los pueblos sólo ha sido para un 10\% aproximadamente, el otro 90\% sigue sufriendo por desempleo y adicciones (https://polivalencia.com/loscasinos-indios-en-estados-unidos-2/ consultada el 15 de agosto de 2017, s.f.).

En la actualidad existen alrededor de 75 ordenamientos en relación a las tribus 
amerindias de los Estados Unidos, comenzando por la enmienda número 14 de la Constitución Norteamericana, tienen relación con la definición de sus territorios, la competencia de la corte tribal, los delitos de las tribus, la administración de sus bienes, sus artesanías, sus derechos civiles, la salud, desarrollo tecnológico y la educación, el bienestar infantil; la prevención de adicciones y de la violencia intrafamiliar; la libertad religiosa, la protección de sus sitios sagrados, entre otros.

\section{Análisis comparativo de los distintos sistemas jurídicos en relación a las comunidades autóctona, tribus o pueblos amerindios (México y Estados Unidos de Norteamérica).}

Una vez estudiadas las comunidades autóctonas en México y las tribus amerindias en los Estados Unidos de Norteamérica podemos distinguir su situación jurídica de la siguiente manera:

El reconocimiento de las comunidades autóctonas en México es en realidad reciente, podemos decir que a partir de la reforma Constitucional de 1992, y específicamente con la reforma de 2001, antes de esta fecha, no había ni reconocimiento, ni tratamiento en la legislación, para estos grupos.

Por el contrario en los Estados Unidos de América, desde la Colonia se hablaba de tratados con los pobladores originarios, para garantizar sus territorios, posteriormente la Constitución y actualmente poseen un amplio ordenamiento en relación a estos pueblos para garantizar su autonomía, sus derechos civiles, la jurisdicción sobre su territorio, su libertad religiosa, etc.

En relación a la organización del Estado mexicano para el conocimiento de las comunidades autóctonas (número, lugar de asentamiento, índice de marginación, conocimiento de sus líderes, etc.), podemos decir que sí existe un conteo aproximado de sus miembros, de las lenguas habladas, de los índices de pobreza, etc., de acuerdo con el último censo de población, del Consejo Nacional de Población y de la Comisión de Asuntos Indígenas, pero no un registro específico de cada una. Además, no podemos hablar de un criterio específico en relación a cómo definir la pertenencia a una Comunidad. 
Sin embargo, es de llamar la atención la organización del Estado norteamericano, a través de la Oficina de Asuntos Indígenas tiene todo un registro pormenorizado de las tribus por Estado, el número de sus habitantes, su territorio, su líder y todos los datos de localización. Criterios que también se aplican para determinar la pertenencia de una persona a determinada tribu y dicho registro les da el carácter de ente colectivo con derechos y obligaciones.

Además, el Departamento del Interior (DOI) de los Estados Unidos que gestiona y administra los programas relacionados con los pueblos indígenas a través de la Oficina de Asuntos Indígenas, cuenta con un presupuesto de 16.8 billones de dólares (Departamento del Interior de los Estados Unidos de Norteamerica, 2017), lo que en un primer momento expresa el interés del gobierno norteamericano en estos pueblos.

En relación a la autonomía y libre determinación, en México, tienen las comunidades autóctonas el reconocimiento desde la Constitución aunque como ha quedado ya plasmado en el transcurso de la investigación, quedan aspectos por definir, además no cuentan con la personalidad jurídica para la defensa de dicha autonomía. La autonomía de estos pueblos como muchos de América Latina, se ha logrado a través de constantes luchas por la preservación de su cultura.

En los Estados Unidos sí está prevista la libre determinación y autonomía, se les llama también naciones soberanas, algunas tienen una Constitución propia, tienen personalidad jurídica para acudir a la defensa de sus derechos, cuentan una oficina de justicia tribal, sin embargo, hay cuestiones que nos hacen pensar que la realidad es distinta, al tener los pueblos amerindios solo el fideicomiso de las tierras que forman la reservación, pues su territorio es trust land o territorio federal y sólo se dedican a la administración de programas federales. Además, toda la industria relacionada con los juegos de azar es otro medio de dominación y la decisión de otorgar el permiso para establecer un casino en las reservas indígenas es en un primer momento de la Federación, condicionado a la ley del Estado correspondiente.

El Estado norteamericano tiene una población pluriétnica, multicultural, varias razas que conviven con un fin común, the american stylelife o sueño americano, donde los jóvenes de los grupos étnicos son atraídos por esta forma de vida, olvidando su tradición cultural, buscando la asimilación. 


\section{Conclusiones}

Los mexicanos somos sincréticos, una fusión de dos formas de interpretar la vida: la española y la indígena de manera principal. Para conocernos, preservar nuestra cultura y nuestra nación, debemos de entender y respetar nuestra parte prehispánica, precuauhtemica o autóctona.

Las comunidades autóctonas en México tienen una problemática muy específica de discriminación, expoliación, transculturación y de un constante proceso de colonización, donde el Estado mexicano no ha determinado las bases suficientes para la defensa de sus derechos.

En relación a la historia de los derechos reconocidos de las comunidades autóctonas en la historia del constitucionalismo mexicano, se les contempla en dos textos constitucionales (1824 y 1917), pero como una copia de la Constitución norteamericana, que no reflejaron soluciones a los problemas de dichas comunidades en su contexto histórico..

En relación a la presión internacional, con motivo de los 500 años del descubrimiento de nuestro continente y con el anhelo de entrar al proceso globalizador con el Tratado de Libre Comercio, el tema indígena se colocó en los primeros planos de la discusión nacional, así el gobierno mexicano decidió reformar nuestra norma rectora en 1992, para reconocer la composición pluricultural de México, esta reforma no tuvo mayor trascendencia, incluso nunca se emitió una ley reglamentaria.

Los movimientos sociales en México se fueron incrementando, se gestó el Ejército Zapatista de Liberación Nacional y tras el movimiento armado de 1994 tuvo lugar el mayor proceso de reflexión, análisis y consenso que tengamos memoria sobre los derechos de los pueblos autóctonos. Así, la lucha por el reconocimiento de autonomía y libre determinación de las comunidades autóctonas de México, trajo como consecuencia una segunda reforma constitucional en 2001.

En este sentido, las comunidades precuauhtemicas, cuentan con un núcleo autonómico y unas competencias delimitadas hasta cierto punto dentro de la Constitución Política de México; sin embargo, si un particular, el Estado, cualquier poder o nivel de gobierno, invade su libre determinación o autonomía constitucional, no cuentan con la personalidad jurídica ni los mecanismos de 
defensa para protegerse; por lo que es necesario el reconocimiento como sujetos de derecho público desde la Constitución.

En México no hemos sido capaces de crear una nación, identidad y Estado, por lo tanto, no existe una ciudadanía activa, participativa, democrática y republicana a través de la cual podamos establecer pactos, de ahí a lo grupal, comunitario, municipal regional y a lo nacional, el "México pluricultural, plurirracial, no existe somos, una entelequia".

En el marco de Derecho Comparado, en los Estados Unidos de Norteamérica las tribus o pueblos amerindios han pasado por diversas etapas desde la aniquilación hasta el reconocimiento, cuentan con un amplio marco jurídico en relación a derechos y oportunidades, sin embargo, no podemos hablar de una autonomía real de estos pueblos, no tienen un territorio propio y la industria del juego va aniquilando su cultura.

\section{Bibliografía}

Affairs, D.o. (2011). Tribal Leaders Directory. USA: USA Gouvernement. Bonilla Maldonado, Daniel. (2006). La constitución multicultural. Colombia: Universidad de los Andes-Facultad de Derecho.

Census. (2010). Obtenido de http://2010.census.gov/2010/census/data consultada el 4 de septiembre de 2011.

Centro de estudios municipales. (2016). Información básica de los municipios en México. México: Secretaría de Gobernación.

Comisión Nacional para el desarrollo de los pueblos indígenas. (2007).

La vigencia de los derechos indígenas en México. México: Gobierno de la República.

Covarrubias Dueñas, José de Jesús. (2014). Dos siglos de constitucionalismo en México. México: Porrúa.

Departamento del Interior de los Estados Unidos de Norteamérica.

(2017). Obtenido de https://gobierno.usa.gov/agencias-federales/ departamento-del-interior consultada el 27 de julio de 2017. 
Estadisticas históricas del INEGI. (2010). México: Instituto Nacional de Estadística y Geografía.

Florescano, Enrique. (1998). Etnia, Estado y Nación, Ensayo sobre entidades colectivas en México. México: Aguilar.

González Gutiérrez, C. (1996). Entre la asimilación y el multiculturalismo.

En R.F. Fernández de Castro, ¿Qué son los Estados Unidos? México: MacGraw Hill, ITAM.

González Galván, Jorge Alberto. (2010). El estado, los indígenas y el derecho. México: UNAM.

Hernández de León Portilla, Ascensión. (2011). El náhuatl y el tronco lingüístico yutonahua. Arqueología Mexicana, Volumen XIX, número 109.

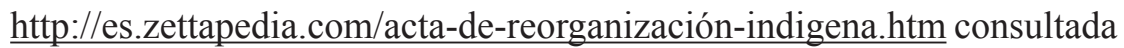

el 15 de septiembre de 2011. (s.f.)

https://polivalencia.com/los-casinos-indios-en-estados-unidos-2/

consultada el 15 de agosto de 2017.

Instituto de Estudios del Federalismo. (2003). Derechos Humanos de las

Etnias Jaliscienses. Guadalajara, Jalisco: Gobierno del Estado de Jalisco.

Los casinos de las tribus estadounidenses: ¿un punto para la autodeterminación? (s.f.) obtenido de http://www.scielo.org.mx consultada el 15 de septiembre de 2011.

Miranda Torres, Roxana, Covarrubias Dueñas, José de Jesús. (2008).

La Nomología de las Comunidades Precuauhtemicas en México.

México: Gobierno de Oaxaca.

Pevar, Stephen. (2002). The rights of indians and tribes. Ilinois, USA: Southern, IlionoisUniversity Press.

Prucha,Francis Paul (1997). American Indian Treaties: the history of a political Anomaly. California, USA: University of California Press. Toinet, Marie France. (1994). El Sistema politico de los Estados Unidos.

México. Fondo de Cultura Económica.

www.inegi,com.mx consultada el 14 de agosto de 2017. Zamudio, Teodora. (2011). Derechos de los Pueblos indígenas, 
las tribus indígenas de los Estados Unidos. Buenos Aires Argentina: Centro de recursos informativos de la Embajada de los Estados Unidos. 